\title{
Effect of Being Housewife and Counseling During Antenatal Care on Exclusive Breastfeeding Practice Among Mothers with Less than Two Years of Age in Northeast Ethiopia, 2019
}

Wolde Ayele ( $\nabla$ wolde400@gmail.com )

\section{Research}

Keywords: Exclusive breastfeed, Prevalence, Northeast Ethiopia

Posted Date: June 2nd, 2020

DOl: https://doi.org/10.21203/rs.3.rs-32071/v1

License: (c) (1) This work is licensed under a Creative Commons Attribution 4.0 International License. Read Full License 


\section{Abstract}

Background Exclusive breastfeeding is the practice of a woman feeding an infant for six months, which has an irreplaceable benefit. However, the practice is still low with salient factors in a different place. Therefore, this study was aimed to assess exclusive breastfeeding practice and associated factors among mothers of having children less than two-years of age in Northeastern Ethiopia, 2019.

Methods A community-based cross-sectional study was conducted with a sample size of 423 in Northeast Ethiopia from March 12 to December 18, 2019. An interviewer-administered questionnaire was used to collect the data. The binary logistic regression model was used to determine the association between dependent and independent variables.

Result The prevalence of exclusive breastfeeding practice was $75.5 \%(95 \% \mathrm{Cl}: 73.5,81.5 \%)$. Married mothers $2.57(1.688,5.654)$, mothers with antenatal care follow up 4.11(2.662,11.172), mothers delivered at health institution 4.07(2.992,10.722), and mothers counseled during antenatal care 1.96(1.124,4.732) had a positive association, while mothers with unable to read and write educational status $0.11(0.068,0.992)$ and employed mothers $0.22(0.169,0.561)$ were the variable that had a negative association with exclusive breastfeeding practice.

Conclusion The prevalence of exclusive breastfeeding practice was relatively good. Marital status, educational status, occupation, antenatal care service, place of birth, and counseling of mothers during ANC were the independent predictors of exclusive breastfeeding practice.

\section{Background}

Breastfeeding is the practice of a woman feeding an infant \& young child(1), which has extreme product given to a baby, natural food, and uniquely adapted to baby's needs(2).

Breast milk contains all the essential nutrients that a healthy child needs(3). World Health Organization (WHO) infant-feeding guidelines recommend that all infants should be breastfed within one hour of birth and exclusively breastfed until six months of life. Optimal feeding of infants and children means exclusive breastfeeding from birth to six months. It is followed by the introduction of complementary foods drawn from the local diet at about six months(4). Currently it is only $39 \%$ of all infants who are exclusively breastfed worldwide. The prevalence is about $30 \%$ in most developing world countries. Globally, because of inadequate breastfeeding practice in combination with high levels of diseases, more than 10 million under five-years of children die each year. Of this figure, $41 \%$ occur in sub-Saharan Africa and $34 \%$ in South Asia region(5). A cohort study carried out in Ghana revealed that $22 \%$ of neonatal deaths could be prevented if all infants were breastfed within the first hour of birth(6). It has also been reported that exclusive breastfeeding from birth and until 6 months of age has the potential to prevent $13 \%$ of all deaths among children, aged less than 5 years, annually in developing countries (7). Study in Addis Ababa showed that $60.0 \%$ of mothers gave pre-lacteal fluids and $32.0 \%$ infants less than four months were exclusively breastfed(8). There is a wide range of variation in the practice of exclusive 
breastfeeding among developing countries, with the rates documented being: Brazil (58\%), Bangalore (40\%), Iran (69\%), Beruwala (15.5\%), Lebanon (10.1\%), Nigeria (20\%), Bangladesh (34.5\%), and Jordan (77\%). In Ethiopia, $49 \%$ of infants for the first six months, and $56.9 \%$ were exclusively breastfed for the first four months(9). According to 2016 EDHS, Ethiopia, 58\% (10), in Jimma 64.4\% (11), in Bishoftu town, Ethiopia $67.2 \%$ (12), in Dabat 18.0\%(13), 99.1\% started breastfeeding within the first hour after birth and 41.8\% prevalence of EBF(14). Similarly, a study in Debre Tabor, Ethiopia, 70.8\%(15), Enderta, Ethiopia, 70.2\% (16), and Motta, Amhara Region, Ethiopia, 50.1\%(17), Guba town, Oromia Region, Ethiopia, 71.3\% (18) and in Gondar town 35.9\% (19) practiced EBF for six months.

The salient factors associated with exclusive breastfeeding are maternal age, maternal level of education, maternal employment status, maternal knowledge, place of delivery, residence, culture, and household wealth status $(11,12,15,17,19)$.

\section{Methods}

Study area and participants

A community-based cross-sectional study was conducted from March 12 to December 182019 in six districts of Northeastern Ethiopia. The study was among mothers who had less than two years of age child. The districts were selected using simple random sampling lottery method among 21 districts.

The sample size was calculated using a single population proportion formula by considering the following assumptions; proportion (50.1\%) of excessive breastfeeding from the study in Motta town, Ethiopia(17). The level of confidence $95 \%$, margin of error $(d)=5 \%$ and $10 \%$ non-response rate. Using a simple random sampling technique 423 mothers participated in the study. To select study participants from each district, first the sample size was proportionally allocated to size and finally a lottery method was used to select each study participant. The actual age of the infant was determined by asking the mothers and reviewing the birth certificate.

\section{Data collection procedure}

An interviewer-administered structured questionnaire was applied for data collection. The questionnaire was designed originally in English and translated to local (Amharic) language for the purpose of data collection and then the results were entered by the English version. It was constructed by adopting from Ethiopian Demographic and Health Survey (EDHS) 2016 (10) and from the previous research done on similar topics $(17,20,21)$ and modified accordingly. The mothers recall method on an infant's diet was used for assessing excessive breastfeeding.

\section{Operational definition}

Exclusive breast-feeding: Exclusive breast-feeding means breast feed a baby duration of 6th months and a frequency of 8-12 times per day $(1,22)$. 
Complementary feeding: Means the provision of other foods or liquids along with breast milk after six month of life(23).

\section{Data processing and Analysis}

he collected data were checked and cleaned manually for completeness, and then it was coded and entered in Epi Info version 3.5.3 and exported to SPSS version 23 for advanced analysis. Descriptive statistics of socio-demographic characteristics and the prevalence of exclusive breastfeeding were used. Binary logistic regression was carried out to identify factors associated with exclusive breastfeeding practice. First bivariable logistic regression was performed to each independent variable with the outcome variable, and those variables with a p-value $<0.2$, were fitted in the final (multivariate analysis) model. The strength of association was measured using odds ratio, and $95 \%$ confidence intervals. Statistical significance was declared at a p-value $<0.05$.

\section{Result}

\section{Socio-demographic characteristics}

A total of 423 mothers with a child less than two years of age participated with a response rate of $96.4 \%$. More than half (52\%) of mothers were between 25-34 years of age. From the study, participants were most $(89.2 \%)$ married $62.7 \%$ housewives and $65 \%$ Muslim religious followers. Regarding educational status more than half were either unable to read and write $(15.4 \%)$ or able to read and write but did not have formal educations (43,8\%). Smallest (7.3\%) and highest (47.7\%) proportion of mothers had less than 1000 and greater than 2500 Ethiopian birr monthly income at household level respectively (Table 1). 
Table 1

Socio-demographic characteristics of mothers and children $(n=408)$ in Northeast Ethiopia, 2019

\begin{tabular}{|c|c|c|c|}
\hline Variable & Category & Frequency & Percentage (\%) \\
\hline \multirow[t]{3}{*}{ Age of mother } & $15-24$ & 115 & 28 \\
\hline & $25-34$ & 212 & 52 \\
\hline & $35-44$ & 81 & 20 \\
\hline \multirow[t]{5}{*}{ Marital status of mother } & Married & 364 & 89.2 \\
\hline & Single & 9 & 2.3 \\
\hline & Divorced & 11 & 2.6 \\
\hline & Separated & 15 & 3.8 \\
\hline & Widowed & 9 & 1.9 \\
\hline \multirow[t]{3}{*}{ Religion of mother } & Orthodox & 132 & 32.3 \\
\hline & Muslim & 265 & 65 \\
\hline & Protestant* & 11 & 2.7 \\
\hline \multirow[t]{3}{*}{ Occupational status of mother } & House wife & 256 & 62.7 \\
\hline & Employee & 150 & 36.9 \\
\hline & Merchant & 2 & 0.4 \\
\hline \multirow[t]{3}{*}{ Occupational status of husband } & Farmer & 158 & 38.8 \\
\hline & Government employer & 226 & 54.6 \\
\hline & Merchant & 24 & 5.8 \\
\hline \multirow[t]{4}{*}{ Educational status of mother } & Unable to read/write & 63 & 15.4 \\
\hline & Able to read and write & 179 & 43.8 \\
\hline & Primary education & 96 & 23.5 \\
\hline & Secondary education & 70 & 17.3 \\
\hline \multirow[t]{3}{*}{ Monthly income } & $<1000$ & 19 & 7.3 \\
\hline & $1001-2500$ & 117 & 45 \\
\hline & $>2500$ & 124 & 47.7 \\
\hline \multirow[t]{2}{*}{ Sex of child } & Male & 225 & 55.1 \\
\hline & Female & 183 & 44.9 \\
\hline
\end{tabular}




\begin{tabular}{|llll|}
\hline Variable & Category & Frequency & Percentage (\%) \\
\hline Age of child(month) & $<6$ & 80 & 19.8 \\
& $\geq 6$ & 328 & 80.2 \\
\hline
\end{tabular}

\section{Maternal Health Services Utilization and related characteristics}

A majority $342(83.8 \%)$ of 408 eligible mothers had an antenatal visit in this study, of whom more than half $212(61.9 \%)$ had four and above visiting. Similarly, more than four-fifth $298(87.1 \%)$ of the mothers who had antenatal service, were counseled about the importance and practice of exclusive breastfeeding (Table 2).

Table 2

Maternal and child health service utilization characteristics of study participants in Northeast Ethiopia, 2019

\begin{tabular}{|c|c|c|c|}
\hline Variable & Category & Frequency & Percentage \\
\hline \multirow[t]{2}{*}{ ANC visit } & Yes & 342 & 83.8 \\
\hline & No & 66 & 16.2 \\
\hline \multirow[t]{3}{*}{ ANC visit category $(N=342)$} & One & 10 & 2.7 \\
\hline & $\begin{array}{l}\text { Two or } \\
\text { three }\end{array}$ & 120 & 35.2 \\
\hline & $\begin{array}{l}\text { Four and } \\
\text { above }\end{array}$ & 212 & 61.9 \\
\hline \multirow[t]{2}{*}{ PNC follow up } & Yes & 312 & 76.5 \\
\hline & No & 96 & 23.5 \\
\hline \multirow[t]{2}{*}{ Place of delivery } & Home & 74 & 18.2 \\
\hline & $\begin{array}{l}\text { Health } \\
\text { facility }\end{array}$ & 334 & 81.8 \\
\hline \multirow[t]{2}{*}{ Breastfeeding counsel during ANC } & Yes & 298 & 87.1 \\
\hline & No & 46 & 12.9 \\
\hline \multirow{2}{*}{$\begin{array}{l}\text { Culture(ingest butter at birth, make child to test foods what } \\
\text { mother take, etc.) before six months age }\end{array}$} & Yes & 218 & 53.4 \\
\hline & No & 190 & 46.6 \\
\hline
\end{tabular}


Two hundred sixty-eight (65.8\%) of 408 mothers put their newborns to breastfeed within one hour of birth. But, only $30(7.3 \%)$ of mothers initiated breastfeed let after one day. Three hundred and fifty-one (86\%) of 408 mothers did not give food other than breast milk within the first three days of birth. The prevalence of exclusive breastfeeding practice in this study was $77.5 \%(95 \% \mathrm{Cl}: 73.5,81.5 \%)$. This was computed from mothers who have six and above years of age child during data collection.

Among mothers who still breastfeeding during the survey, 147(36.2\%) were nursing their child less than 8 times per day, but the highest 227(55.8\%) of mothers were breastfeeding $8-12$ times per day. One hundred one (24.7\%) of 408 mothers were breastfeeding while their child is crying (Table 3 ). 
Table 3

Breast feeding practice of mother having child less than 2 years, Northeast Ethiopia, 2019.

\begin{tabular}{|c|c|c|c|}
\hline Practice of mother for child feed & Category & Frequency & Percentage \\
\hline \multirow[t]{3}{*}{ Breastfeeding initiation } & Immediately & 268 & 65.8 \\
\hline & After 1 hour & 110 & 26.9 \\
\hline & After day & 30 & 7.3 \\
\hline \multirow{2}{*}{$\begin{array}{l}\text { Gave food other than breast milk in first } 3 \text { days of } \\
\text { birth }\end{array}$} & Yes & 57 & 14 \\
\hline & No & 351 & 86 \\
\hline \multirow[t]{3}{*}{ Types of food given } & plain water & 27 & 47.2 \\
\hline & sugar solution & 19 & 33.3 \\
\hline & cow milk & 11 & 19.4 \\
\hline \multirow{2}{*}{$\begin{array}{l}\text { No food given other than breast milk before six } \\
\text { month }(\mathrm{N}=328) \text { ? }\end{array}$} & Yes & 255 & 77.5 \\
\hline & No & 73 & 22.5 \\
\hline \multirow[t]{2}{*}{ When do you usually feed the child? } & $\begin{array}{l}\text { Child likes to } \\
\text { have }\end{array}$ & 307 & 75.3 \\
\hline & $\begin{array}{l}\text { When child } \\
\text { cries }\end{array}$ & 101 & 24.7 \\
\hline \multirow[t]{3}{*}{ No of breast milk feed per day } & $<8$ & 147 & 36.2 \\
\hline & $8-12$ & 227 & 55.8 \\
\hline & $>12$ & 34 & 8.1 \\
\hline \multirow[t]{3}{*}{ Age child in month when they stop breast feed } & $\leq 16$ & 119 & 29.2 \\
\hline & $17-23$ & 185 & 45.3 \\
\hline & $>23$ & 104 & 25.5 \\
\hline \multirow{2}{*}{$\begin{array}{l}\text { Start complimentary feeding practice at six month ( } N \\
=209)\end{array}$} & Yes & 185 & 88.6 \\
\hline & No & 24 & 11.4 \\
\hline
\end{tabular}

\section{Factors associated with breastfeeding practice}

After adjusting in multivariable analysis, marital status, educational status, occupation, ANC follow up, birthplace and breastfeeding counseling of mothers were the independent predictors of exclusive breastfeeding practice. Mothers who were in married marital status were $2.57(1.688,5.654)$ times more likely to breastfeed their child exclusively. Likewise, mothers who had antenatal care 4.11(2.662,11.172), institutional delivery $4.07(2.992,10.722)$, and mothers who got breastfeeding counseling during their ANC 
follow up 1.96(1.124,4.732) more odds of exclusive breastfeeding practice compared to their counterparts.

On the other hand, employed mothers were around $78 \%$ less likely to practice exclusive breastfeeding than unemployed housewife mothers. Concerning education, unable to read and write mothers were $89 \%$ less likely to practice exclusive breastfeeding than mothers with secondary and above educational status (Table 4). 
Table 4

Factors associated with exclusive breastfeeding practice among mothers with children age less than two years in Northeast Ethiopia, 2019

\begin{tabular}{|c|c|c|c|c|c|}
\hline \multirow[t]{2}{*}{ Variables } & & \multicolumn{4}{|c|}{$\begin{array}{l}\text { EBF } \\
\text { practice }\end{array}$} \\
\hline & & Yes & No & COR $(95 \% \mathrm{Cl})$ & AOR $(95 \% \mathrm{Cl})$ \\
\hline \multirow[t]{2}{*}{ Marital status } & Married & 238 & 116 & $3.01(1.567,5.808)$ & $2.57(1.688,5.654)$ \\
\hline & Not married & 17 & 25 & 1 & \\
\hline \multirow[t]{4}{*}{ Educational Status } & $\begin{array}{l}\text { Unable to } \\
\text { read/write }\end{array}$ & 17 & 46 & $0.72(0.342,0.1 .270)$ & $0.11(0.068,0.992)$ \\
\hline & $\begin{array}{l}\text { Able to read } \\
\text { and write }\end{array}$ & 89 & 90 & $0.48(0.271,0.863)$ & \\
\hline & $\begin{array}{l}\text { Primary } \\
\text { education }\end{array}$ & 50 & 46 & $0.53(0.280,1.008)$ & \\
\hline & $\begin{array}{l}\text { Secondary } \\
\text { education }\end{array}$ & 47 & 23 & 1 & 1 \\
\hline \multirow[t]{2}{*}{ Occupation } & House wife & 200 & 67 & 1 & 1 \\
\hline & Employee & 55 & 86 & $0.21(0.138,0.331)$ & $0.22(0.169,0.561)$ \\
\hline \multirow[t]{2}{*}{ ANC follow up } & Yes & 238 & 99 & $6.92(3.805,12.618)$ & $4.11(2.662,11.172)$ \\
\hline & No & 17 & 49 & 1 & 1 \\
\hline \multirow[t]{2}{*}{ Birth place } & $\begin{array}{l}\text { Health } \\
\text { institution* }\end{array}$ & 232 & 102 & $5.04(2.925,8.694)$ & $4.07(2.992,10.722)$ \\
\hline & Home & 23 & 51 & 1 & 1 \\
\hline \multirow[t]{2}{*}{ PNC follow up } & Yes & 227 & 85 & $6.48(3.911,10.821)$ & \\
\hline & No & 28 & 68 & 1 & \\
\hline \multirow{2}{*}{$\begin{array}{l}\text { Breastfeeding counsel } \\
\text { during ANC }\end{array}$} & Yes & 230 & 63 & $2.77(1.436,5.359)$ & $1.96(1.124,4.732)$ \\
\hline & No & 25 & 19 & 1 & 1 \\
\hline \multirow[t]{2}{*}{ Culture } & Yes & 54 & 164 & $0.35(0.235,0.544)$ & $0.23(0.142,0.462)$ \\
\hline & No & 91 & 99 & 1 & 1 \\
\hline
\end{tabular}

\section{Discussion}

Breast milk is the very irreplaceable food to a newborn baby; it uses the baby to grow properly, protect the newborn from infection because it has antibodies. This study revealed that the prevalence of exclusive breastfeeding was $77.5 \%(95 \% \mathrm{Cl}: 73.5,81.5 \%)$. Despite its need, the prevalence of exclusive breastfeeding 
in this study was not as satisfactory. However, it was higher compared to the Ethiopian demographic health survey (EDHS) 16 data (58\%) (10), the global EBF estimate 35\%, and in developing countries such as; Motta town, Ethiopia (17), Nigeria (20\%), Brazil (58\%), Bangladesh $(34.5 \%)(1,4,11,19)$. In contrast, this result was comparable with the study in Addis Ababa (81\%)(24), Ethiopian HSDP IV target level of 70\% (25), and Debre Markos, Ethiopia 60.8\% (21).

Initiation of EBF during an hour after delivery is recommended to prevent $13 \%$ of child death(7), protect infants from otitis media for at least four months (26). In this study, the higher prevalence $(65.8 \%)$ of mothers was initiated breastfeeding within one hour after delivery. This result was congruent with the studies in Amhara (60\%), Oromia (77\%), and Southern Ethiopia (50\%)(27). Whereas, it was higher compared to a study in Dabat, Gondar (23.2\%)(13), and lower from a study in Tigray (99.1\%)(16). These variations might be due to incomparable sample size, study designs used and study setting (community based and institutional) difference of the study areas.

Concerning factors associated with breastfeeding practices like mother's level of education, marital status, occupation, ANC, place of delivery, and counseling about breastfeeding practice during ANC visit were the variables that significantly associated with exclusive breastfeeding practice.

The study showed that the odds of exclusive breastfeeding among mothers having an educational level unable to read and write $89 \%$ less likely than mothers who have secondary and above educational levels. This is a discordant result when compared to study determinants of exclusive breastfeeding in Ethiopia(28).

After controlling the confounding variables, unemployed(housewife) mothers practiced EBF better than employed mothers. Employed mothers were about $78 \%$ less practiced exclusive breastfeeding than housewife mothers. This result is similar to studies in Malaysia $(29,30)$, Cameroon $(31)$, Ghana $(32,33)$, Awi Zone, Ethiopia (34), Northwest Ethiopia(35), and Debre Markos, Ethiopia(21). This might because women spent their time at home are more frequently in contact with their child.

This study revealed that mothers who had antenatal care had four times more likely of practicing exclusive breastfeeding practice. This is supported by a nested case-control study in Northwest, Ethiopia(36), Jima, Ethiopia (37), and breastfeeding guidelines(38, 39). However, it has no association with EBF practice according to a study in Motta town, Ethiopia(17). This might be attributed to the study year (the former is conducted five years back), and the study population included.

Mothers who gave birth in a health institution were more likely to practice exclusive breastfeeding compared with those who gave birth at home. This finding had in agreement with the studies done at Bahir Dar, Ethiopia(33) and Ghana(32). This could be due to the fact that mothers who give birth in institution have more opportunities to be counseled about the benefit of breastfeeding by health care providers. In contrast to this, study done in Motta, Ethiopia indicated that birth place do not associate with exclusive breast feeding practice. This discrepancy might be due to the study period, study populations and sociocultural difference. 
In this study breastfeeding counseling during antenatal care service was found to facilitate exclusive breastfeeding practice. This is parallel with studies done with low income Latinos in United states (40), Nigeria(41), and Debre Markos, Ethiopia(21). This could be health education and counseling increases mothers' knowledge about the need and benefits of EBF.

Culture was one of the independent predictor of exclusive breastfeeding in this study. The study showed that mothers who had a culture of giving different prelacteal foods (like; water, coffee, fresh butter, etc.) were around $80 \%$ less likely practicing of exclusive breastfeeding. This was in line with studies in Afar, Ethiopia(42), avoidance of prelacteal practice in rural Ethiopia(43), and a study exclusive breast feeding measurements and indicators in Israel (44). This might be the fact that, most Ethiopian mothers believe that their child will be affected by the devil if they did not make their child test a portion of food that the mothers tested (visual witness from elders).

Although a cross-sectional study design was used, this study had a strength of inclusion of large study areas. However, the limitations of this study were unable to assess qualitative aspects; like the attitude of both parents towards exclusive breastfeeding, factors related to health institutions, and detailed cultural factors like ingesting fresh butter to the infant at birth. Likewise, since this study included mothers with up to two years of a child, recall bias might under/overestimate the prevalence of exclusive breastfeeding.

\section{Conclusion}

This study revealed an appreciable prevalence of breastfeeding. Being married, having antenatal follow up, institutional delivery, and counseling about breastfeeding during antenatal service were the variables that increase exclusive breastfeeding practice. While, unable to read and write educational status and being employed were the negative factors for exclusive breastfeeding.

\section{Abbreviations}

ANC

Antenatal Care, AOR:Adjusted Odds Ratio, EBF:Exclusive Breast Feeding, HSDP:Health Sector Development Plan, OR:Odds Ratio, PNC:Postnatal Care

\section{Declarations}

\section{Ethical approval and consent to participate}

Ethical clearance was insured from Wollo University, College of Medicine and Health Sciences ethical review committee. Verbal consent was obtained from each study participants after clarifying of the objective of the study. They were also told their rights in discontinuing or not responding of the interview. Data collection was taken Confidentiality of information collected is kept anonymously. 


\section{Consent for publication}

Not applicable

\section{Availability of data and materials}

All the necessary data are included in the manuscript.

\section{Competing Interests}

The author declared that there is no competing interest

\section{Funding}

This investigation received no specific grant from funding agency in public commercial, or for profit sectors.

\section{Authors' contributions}

\section{WMA is the author involved in the design, implementation, data cleaning, and analysis and draft the manuscript. The author has read and approved the manuscript.}

\section{Acknowledgments}

I am grateful to thank Wollo University, college of medicine, and the health sciences ethical review committee. I also want to gratify all health extension workers working in the study area for their voluntary data collection. The study participants accordingly acknowledged their voluntary response to the interview. Finally, I obligated to acknowledge Tesfaye Birhane and Shambel Wodajo for their support in data analysis and final manuscript editing.

\section{References}

1. Organization WH. Infant and young child feeding: model chapter for textbooks for medical students and allied health professionals. 2009.

2. Marcdante K, Kliegman RM. Nelson Essentials of Pediatrics. E-Book: Elsevier Health Sciences; 2014. 
3. Walker AR, Adam FI. Walker BFJTjotRSftPoH. Breast cancer in black African women: a changing situation. 2004;124(2):81-5.

4. Organization WH. Global strategy for infant and young child feeding: World Health Organization; 2003.

5. Mahoney MC, James DMJJoFP. Predictors of anticipated breastfeeding in an urban. low-income setting. 2000;49(6):529-.

6. Aidam BA, Perez-Escamilla R, Lartey A, Aidam JJEjocn. Factors associated with exclusive breastfeeding in Accra. Ghana. 2005;59(6):789-96.

7. Edmond KM, Zandoh C, Quigley MA, Amenga-Etego S, Owusu-Agyei S, Kirkwood BRJP. Delayed breastfeeding initiation increases risk of neonatal mortality. 2006;117(3):e380-e6.

8. Gebru S. Assessment of breastfeeding practice in Yeka sub-city Addis Ababa. Ethiopia; 2007.

9. Cai X, Wardlaw T, Brown DWJIbj. Global trends in exclusive breastfeeding. 2012;7(1):12.

10. EDHS EJTDPI. demographic and health survey 2016: key indicators report. 2016;363:364.

11. Khoushabi F, Shadan M, Chenar S, Bagheri SJPMA. Knowledge and attitude evaluation of mothers regarding exclusive breastfeeding referring to health care centers. 2018;104(5).

12. Biruk K. The status of breastfeeding among mothers of children aged less than two years and implication for the occurrence of acute diarrhea: Masters Thesis, Ethiopia; 2002.

13. Derso T, Biks GA, Tariku A, Tebeje NB, Gizaw Z, Muchie KF, et al. Correlates of early neonatal feeding practice in Dabat HDSS site. northwest Ethiopia. 2017;12(1):25.

14. Getachew G. Feeding profile and diarrheal morbidity among 7-12 month infants in Tigray: Master's Thesis, Ethiopia; 2006.

15. Arage G, Gedamu HJAiPH. Exclusive breastfeeding practice and its associated factors among mothers of infants less than six months of age in Debre Tabor town, Northwest Ethiopia: a crosssectional study. 2016;2016.

16. Teka B, Assefa H, Haileslassie KJIbj. Prevalence and determinant factors of exclusive breastfeeding practices among mothers in Enderta woreda, Tigray, North Ethiopia: a cross-sectional study. 2015;10(1):2.

17. Tewabe T, Mandesh A, Gualu T, Alem G, Mekuria G, Zeleke HJlbj. Exclusive breastfeeding practice and associated factors among mothers in Motta town, East Gojjam zone, Amhara Regional State, Ethiopia, 2015: a cross-sectional study. 2016;12(1):12.

18. Setegn T, Belachew T, Gerbaba M, Deribe K, Deribew A, Biadgilign SJIbj. Factors associated with exclusive breastfeeding practices among mothers in Goba district, south east Ethiopia: a crosssectional study. 2012;7(1):17.

19. Berhanu M, Zemene W, Mekonnen MJAiN. Prevalence and associated factors of nonexclusive breastfeeding to infants within the first 6 months in Gondar town, northwest Ethiopia, 2014. $2015 ; 2015$. 
20. Sefene A, Birhanu D, Awoke W, Taye TJSJCM. Determinants of exclusive breastfeeding practice among mothers of children age less than 6 month in Bahir Dar city administration, Northwest Ethiopia; a community based cross-sectional survey. 2013;2(6):153-9.

21. Mekuria G, Edris MJlbj. Exclusive breastfeeding and associated factors among mothers in Debre Markos, Northwest Ethiopia: a cross-sectional study. 2015;10(1):1.

22. Organization WH. Diet, nutrition, and the prevention of chronic diseases: report of a joint. WHO/FAO expert consultation: World Health Organization; 2003.

23. Giugliani E, Victora CGJJp. Complementary feeding. 2000;76(3):253-62.

24. Shifraw T, Worku A, Berhane YJlbj. Factors associated exclusive breastfeeding practices of urban women in Addis Ababa public health centers, Ethiopia: a cross sectional study. 2015;10(1):22.

25. Health FMo. Ethiopian Health Sector Development Programme IV ed. Addis Ababa: Ethiopian federal minstry of health; 2010.

26. Duncan B, Ey J, Holberg CJ, Wright AL, Martinez FD, Taussig LMJP. Exclusive breast-feeding for at least 4 months protects against otitis media. 1993;91(5):867-72.

27. bālaśeltān EYs, Macro O. Ethiopia Demographic and Health Survey, 2005: Central Statistical Authority; 2006.

28. Alemayehu T, Haidar J, Habte DJEJoHD. Determinants of exclusive breastfeeding practices in Ethiopia. 2009;23(1).

29. Tan KLJIbj. Factors associated with exclusive breastfeeding among infants under six months of age in peninsular Malaysia. 2011;6(1):2.

30. Tan KJIMJM. Knowledge, attitude and practice on breastfeeding in Klang, Malaysia. 2009;8(1).

31. Kakute PN, Ngum J, Mitchell P, Kroll KA, Forgwei GW, Ngwang LK, et al. Cultural barriers to exclusive breastfeeding by mothers in a rural area of Cameroon. Africa. 2005;50(4):324-8.

32. Aidam BA, Perez-Escamilla R, Lartey AJTJon. Lactation counseling increases exclusive breastfeeding rates in Ghana. 2005;135(7):1691-5.

33. Seid AM, Yesuf ME, Koye DNJIbj. Prevalence of Exclusive Breastfeeding Practices and associated factors among mothers in Bahir Dar city, Northwest Ethiopia: a community based cross-sectional study. 2013;8(1):14.

34. Yeneabat T, Belachew T, Haile, MJBp, childbirth. Determinants of cessation of exclusive breastfeeding in Ankesha Guagusa Woreda, Awi Zone, Northwest Ethiopia: a cross-sectional study. 2014;14(1):262.

35. Asemahagn MAJlbj. Determinants of exclusive breastfeeding practices among mothers in azezo district. northwest Ethiopia. 2016;11(1):22.

36. Biks GA, Tariku A, Tessema GAJlbj. Effects of antenatal care and institutional delivery on exclusive breastfeeding practice in northwest Ethiopia: a nested case-control study. 2015;10(1):30.

37. Tamiru D, Belachew T, Loha E, Mohammed SJBPH. Sub-optimal breastfeeding of infants during the first six months and associated factors in rural communities of Jimma Arjo Woreda. Southwest 
Ethiopia. 2012;12(1):363.

38. Bhandari N, Kabir Al, Salam MAJM, nutrition c. Mainstreaming nutrition into maternal and child health programmes: scaling up of exclusive breastfeeding. 2008;4:5-23.

39. Tiwari S, Bharadva K, Yadav B, Malik S, Gangal P, Banapurmath C, et al. Infant and young child feeding guidelines, 2016. 2016;53(8):703 - 13.

40. Kistin N, Abramson R, Dublin, PJJohl. Effect of peer counselors on breastfeeding initiation, exclusivity, and duration among low-income urban women. 1994;10(1):11-5.

41. Agho KE, Dibley MJ, Odiase JI. Ogbonmwan SMJBp, childbirth. Determinants of exclusive breastfeeding in Nigeria. 2011;11(1):2.

42. Tsegaye M, Ajema D, Shiferaw S, Yirgu RJIbj. Level of exclusive breastfeeding practice in remote and pastoralist community, Aysaita woreda. Afar Ethiopia. 2019;14(1):6.

43. Rogers NL, Abdi J, Moore D, Nd'iangui S, Smith LJ, Carlson AJ, et al. Colostrum avoidance, prelacteal feeding and late breast-feeding initiation in rural Northern Ethiopia. 2011;14(11):2029-36.

44. Greiner TJlbj. Exclusive breastfeeding: measurement and indicators. 2014;9(1):18. 